\title{
Osthole suppresses migration and invasion of A549 human lung cancer cells through inhibition of matrix metalloproteinase-2 and matrix metallopeptidase- 9 in vitro
}

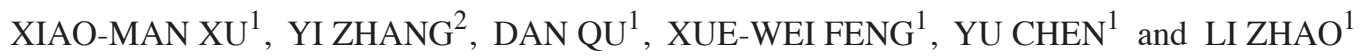 \\ Departments of ${ }^{1}$ Respiratory Medicine, and ${ }^{2}$ Geriatrics, Shengjing Hospital of China Medical University, \\ Shenyang, Liaoning 110004, P.R. China
}

Received April 21, 2012; Accepted August 15, 2012

DOI: $10.3892 / \mathrm{mmr} .2012 .1044$

\begin{abstract}
Osthole, a natural compound, may be extracted from Cnidium monnieri and other medicinal plants. Previous studies have shown that osthole has anticancer effects in various human cancer cell lines. There is, however, no available information concerning the effects of osthole on the migration and invasion of human lung cancer cells. In the current study, we used Transwell assays to demonstrate that osthole inhibited the migration and invasion of A549 human lung cancer cells. Western blot analysis revealed that osthole reduced the levels of matrix metalloproteinase-2 (MMP-2) and matrix metallopeptidase-9 (MMP-9) in the A549 human lung cancer cells. Our findings indicate that osthole may have a novel function as an inhibitor of the metastasis of human lung cancer.
\end{abstract}

\section{Introduction}

Lung cancer is the most common cause of cancer mortality in the world, and non-small cell lung cancer accounts for approximately $80 \%$ of all lung cancers. Non-small lung cancer predominantly comprises adenocarcinomas and squamous cell carcinomas (1-3). Despite advances in multimodality treatment, including surgical management, chemotherapy, radiotherapy and biological therapy, the overall 5-year survival rate of lung cancer in many countries is less than $15 \%$ (4). In addition, metastasis is one of the reasons for the lower survival rate following the radical resection of lung cancers (5). Cancer metastasis is a complex, multistep process that involves cell adhesion, invasion and migration, proliferation and vessel formation $(6,7)$. Therefore, the prevention or inhibition of lung cancer metastasis has important clinical applications for prolonging life and enhancing the quality of life of patients.

Correspondence to: Dr Xiao-Man Xu, Department of Respiratory Medicine, Shengjing Hospital of China Medical University, 36 Sanhao Road, Shenyang, Liaoning 110004, P.R. China

E-mail:xmx061@hotmail.com

Key words: Osthole, A549 lung cancer cells, migration, invasion
Osthole, 7-methoxy-8-(3-methyl-2-butenyl)coumarin (Fig. 1), a natural compound, may be extracted from Cnidium monnieri and other medicinal plants. Previous studies have revealed that osthole has antiproliferative (8), vasorelaxant (9), anti-inflammatory (10), antimicrobacterial (11) and antiallergic (12) properties. Furthermore, the anticancer effect of osthole has been described. It has been reported that osthole is able to abrogate HGF-induced cell scattering, migration and invasion in MCF-7 breast cancer cells (13). Osthole is also capable of inducing apoptosis in HeLa cells and HL-60 leukemia cells $(14,15)$.

In a previous study, we reported that osthole induces $\mathrm{G} 2 / \mathrm{M}$ arrest and apoptosis in A549 human lung cancer cells by modulating the PI3K/Akt pathway (16). However, the effects of osthole on the migration and invasion of human lung cancer cells remain unclear. The purpose of the current study was to investigate the effects of osthole on the induction of migration and invasion in A549 human lung cancer cells. We also aimed to investigate whether the effects of osthole on the migration and invasion of A549 cells were mediated through the inhibition of matrix metalloproteinase-2 (MMP-2) and matrix metallopeptidase-9 (MMP-9). The findings should indicate whether osthole has the ability to inhibit the metastasis of human lung cancer.

\section{Materials and methods}

Reagents and chemicals. Osthole was purchased from the National Institute for the Control of Pharmaceutical and Biological Products (Beijing, China). A $50 \mathrm{mM}$ stock solution of osthole was dissolved in dimethyl sulfoxide (DMSO) and stored at $-20^{\circ} \mathrm{C}$. RPMI-1640, trypsin, penicillin and streptomycin were purchased from Biological Industries (Kibbutz Beit Haemek, Israel). Fetal bovine serum (FBS) and Giemsa were purchased from Solarbio Science and Technology (Beijing, China). 3-(4,5-Dimethylthiazol-2yl)-2,5-diphenyltetrazolium bromide (MTT) and DMSO were purchased from Sigma-Aldrich (St. Louis, MO, USA). Matrigel and antibodies were purchased from BD Biosciences (San Jose, CA, USA). All other reagents were procured locally.

Cell culture. The A549 human lung cancer cell line was obtained from the China Center for Type Culture Collection 
(Wuhan, China) and maintained in RPMI-1640 supplemented with $10 \% \mathrm{FBS}, 100 \mathrm{U} / \mathrm{ml}$ penicillin and $100 \mu \mathrm{g} / \mathrm{ml}$ streptomycin at $37^{\circ} \mathrm{C}$ in a humidified atmosphere of $5 \% \mathrm{CO}_{2}$.

MTT assay. The proliferation of A549 cells following treatment with osthole was measured using the MTT assay. Briefly, A549 cells were plated at a density of $1 \times 10^{4}$ cells/well in 96 well plates overnight and then treated with various concentrations of osthole $(0,20,40,60$ and $80 \mu \mathrm{mol} / \mathrm{l})$. Following a $24 \mathrm{~h}$ treatment, $20 \mu \mathrm{l}$ MTT solution $(2 \mathrm{mg} / \mathrm{ml}$ in PBS) was added to each well and the cells were cultured for another $4 \mathrm{~h}$ at $37^{\circ} \mathrm{C}$. The medium was then totally removed and $150 \mu \mathrm{l}$ DMSO was added to solubilize the MTT formazan crystals. Finally, the plates were shaken and the optical density was determined at $570 \mathrm{~nm}$ (OD570) using an ELISA plate reader (Model 550, Bio-Rad, Hercules, CA, USA). At least three independent experiments were performed.

Cell migration assay. For the cell migration assay, Transwell chambers were used. Briefly, A549 cells ( $1 \times 10^{5}$ cells/well) were placed in the upper chambers of $8 \mu \mathrm{m}$ Transwells and treated with various concentrations of osthole $(0,40$ and $80 \mu \mathrm{mol} / \mathrm{l})$. The bottom chambers of the Transwells were filled with $0.6 \mathrm{ml}$ RPMI-1640 with $10 \%$ FBS as a chemoattractant. After $24 \mathrm{~h}$, non-migratory cells were carefully removed with a cotton swab. The filter membrane was fixed with cold methanol and acetic acid $(3 / 1, v / v)$ for $30 \mathrm{~min}$, then stained with Giemsa. Images were captured using an Olympus inverted microscope using $\times 200$ magnification and cell migration was quantified by counting the number of cells in 5 random fields. The percentage inhibition of migratory cells was quantified and expressed in relation to the untreated control cells. All experiments were repeated three times.

Cell invasion assay. The invasion assay was performed using the same Transwells as were used in the migration assay. Briefly, A549 cells ( $1 \times 10^{5}$ cells/well) were placed in the upper chambers of matrigel-coated $8 \mu \mathrm{m}$ Transwells and treated with various concentrations of osthole $(0,40$ and $80 \mu \mathrm{mol} / \mathrm{l})$. The bottom chambers of the Transwells were filled with $0.6 \mathrm{ml}$ RPMI-1640 with $10 \%$ FBS as a chemoattractant. Following incubation for $24 \mathrm{~h}$, non-invading cells were carefully removed with a cotton swab. Cells that had penetrated through the matrigel located on the underside of the filter were fixed with cold methanol and acetic acid (3/1, v/v) for $30 \mathrm{~min}$, then stained with Giemsa. The degree of invasiveness was quantified by counting the number of cells in 5 random fields. All experiments were repeated three times.

Western blot analysis. The expression of cellular proteins was evaluated by western blotting. A549 cells were plated onto 6 well plates and starved overnight, then treated with various concentrations of osthole $(0,40$ and $80 \mu \mathrm{mol} / \mathrm{l})$. Following treatment for $24 \mathrm{~h}$, the total proteins were solubilized and extracted with lysis buffer (20 mM HEPES, pH 7.9, 20\% glycerol, $200 \mathrm{mM} \mathrm{KCl,}$ $0.5 \mathrm{mM}$ EDTA, $0.5 \% \mathrm{NP}-40,0.5 \mathrm{mM}$ DTT and $1 \%$ protease inhibitor cocktail). Protein concentrations were determined by bicinchoninic acid (BCA) protein assay. All samples were separated by SDS-PAGE to determine the proteins associated with cell invasion and migration, MMP-2 and MMP-9.

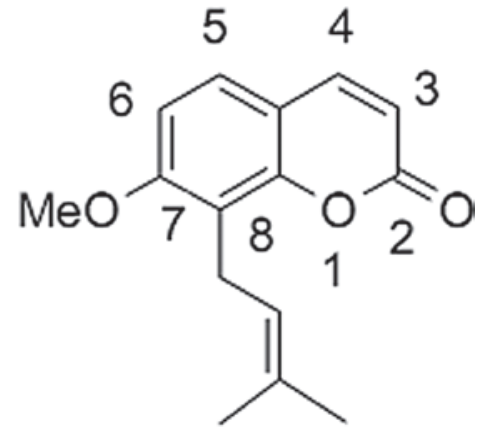

Figure 1. Structure of osthole.

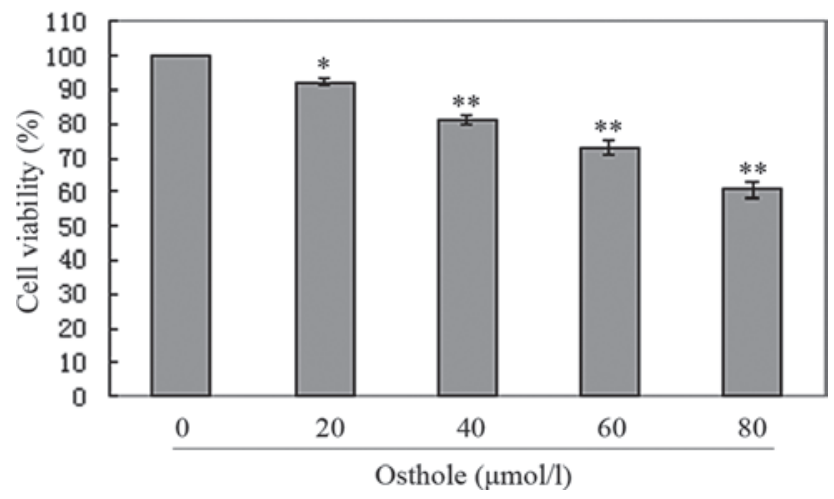

Figure 2. Inhibitory effects of osthole on the proliferation of A549 human lung cancer cells. ${ }^{*} \mathrm{P}<0.05$ vs. the control, ${ }^{* *} \mathrm{P}<0.01$ vs. the control.

Statistical analysis. All experiments were conducted three times. Data were expressed as the mean \pm SD. Statistical correlation of data was checked for significance by ANOVA and the Student's $t$ test. $\mathrm{P}<0.05$ was considered to indicate a statistically significance result. The analyses were performed using SPSS 13.0 software.

\section{Results}

Osthole inhibited A549 cell proliferation. In order to investigate the growth inhibitory effects of osthole, A549 cells were treated with various concentrations of osthole for $24 \mathrm{~h}$ and the rate of inhibition was determined by MTT assay. We observed that the growth of the A549 cells was suppressed in a dosedependent manner (Fig. 2).

Osthole inhibited the migration and invasion of A549 cells in vitro. Transwell assays were performed to investigate the effects of osthole on lung cancer cell migration and invasion. A549 cells were treated with various concentrations of osthole $(0,40$ and $80 \mu \mathrm{mol} / \mathrm{l})$ in order to perform the Transwell migration and matrigel-based Transwell invasion assays. As shown in Fig. 3, the A549 cells migrated from the upper to the lower chamber and this was inhibited by osthole. As shown in Fig. 4, the penetration of the A549 cells through the matrigel to the lower surface of the filter was also inhibited by osthole. These inhibitory effects were higher at an osthole concentration of $80 \mu \mathrm{mol} / 1$ than of $40 \mu \mathrm{mol} / 1$. Our results indicate that osthole significantly inhibits lung cancer cell migration and invasion 
A

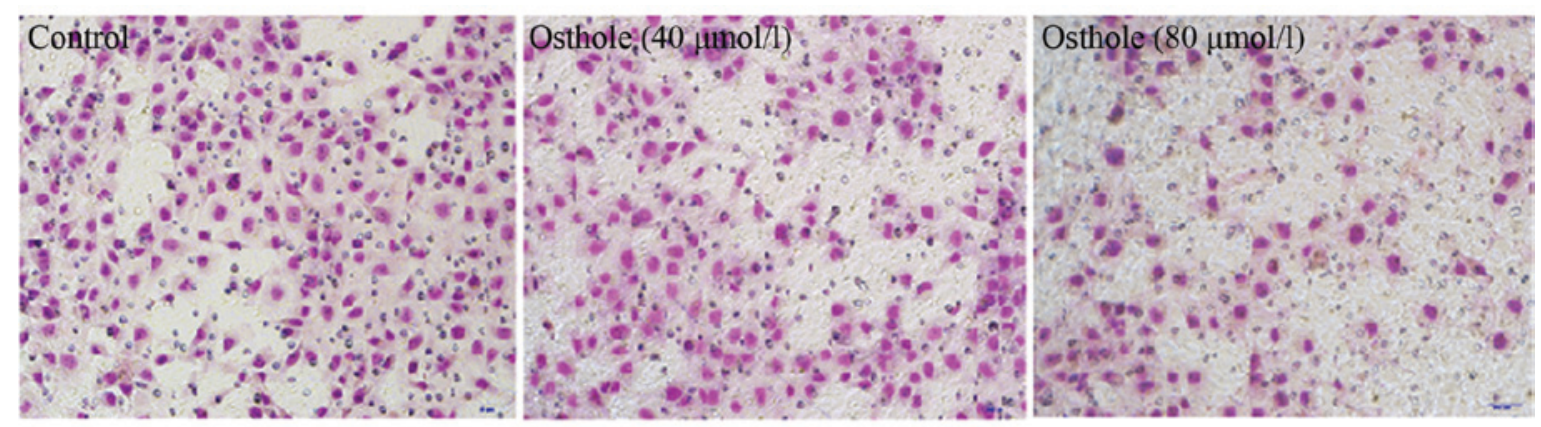

B

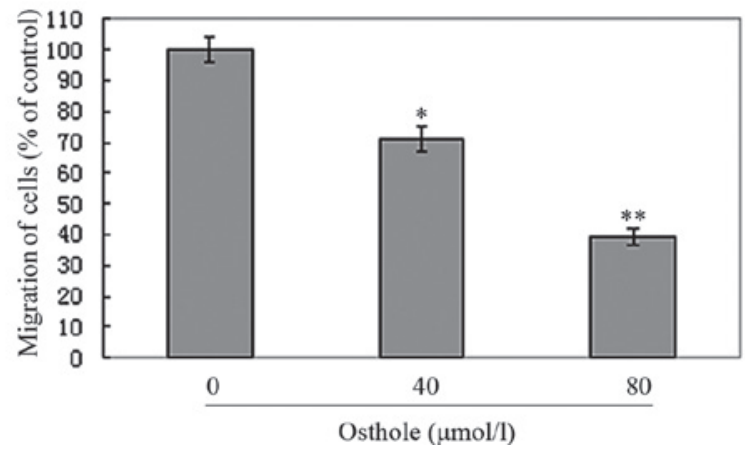

Figure 3. (A) Osthole inhibited the migration of A549 cells. A549 cells were placed in the upper chambers of Transwells and cells that penetrated to the lower surface of the filter were stained with Giemsa and images captured under a light microscope at $\mathrm{x} 200$. (B) Summary of the inhibition data."P<0.05 vs. the control, ${ }^{* *} \mathrm{P}<0.01$ vs. the control.

A

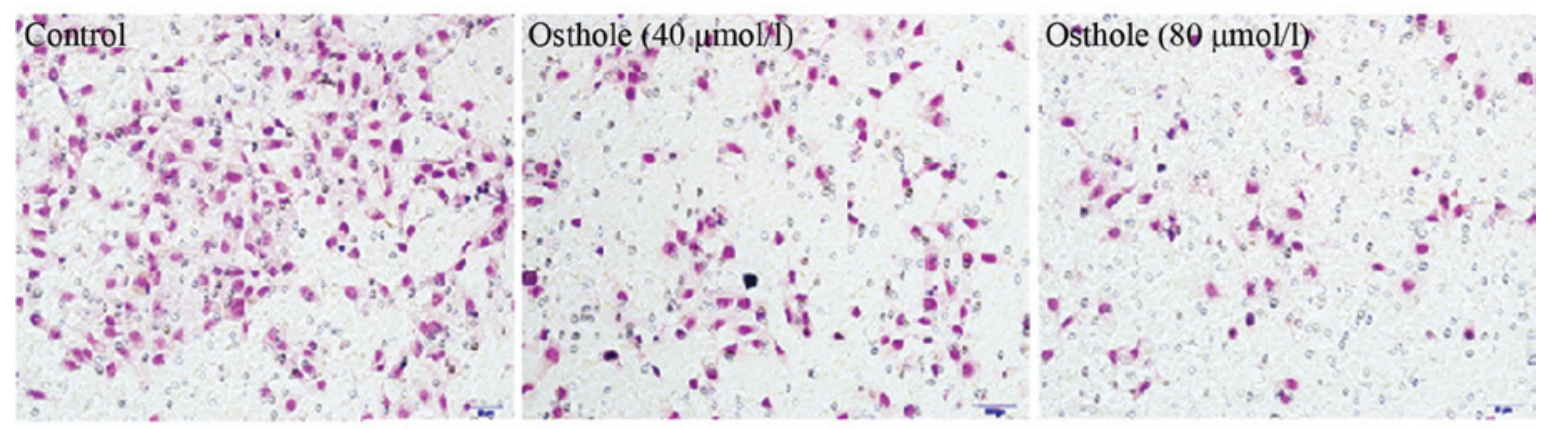

B

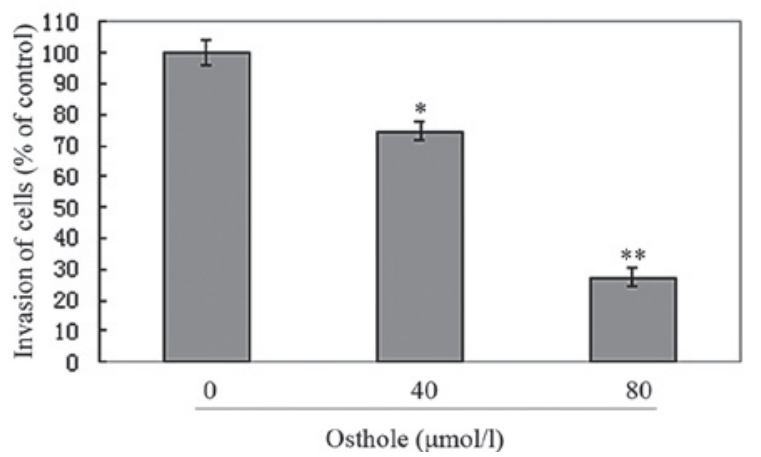

Figure 4. (A) Osthole inhibited the invasion of A549 cells. A549 cells were placed in the upper chambers of Transwells and cells that penetrated through the matrigel to the lower surface of the filter were stained with Giemsa and images captured under a light microscope at x200. (B) Summary of the inhibition data." $\mathrm{P}<0.05$ vs. the control, ${ }^{* *} \mathrm{P}<0.01$ vs. the control.

in a dose-dependent manner, suggesting a crucial role for osthole in the suppression of lung cancer metastasis.

Osthole inhibited levels of MMP-2 and MMP-9 in A549 cells. The levels of migration- and invasion-associated proteins during the treatment with osthole were examined by western blotting. As shown in Fig. 5, the levels of MMP-2 and MMP-9 in the osthole-treated cells were lower than those in the control cells. MMP-2 and MMP-9 are significant in lung cancer cell invasion and migration. The inhibitory effects on MMP-2 and 


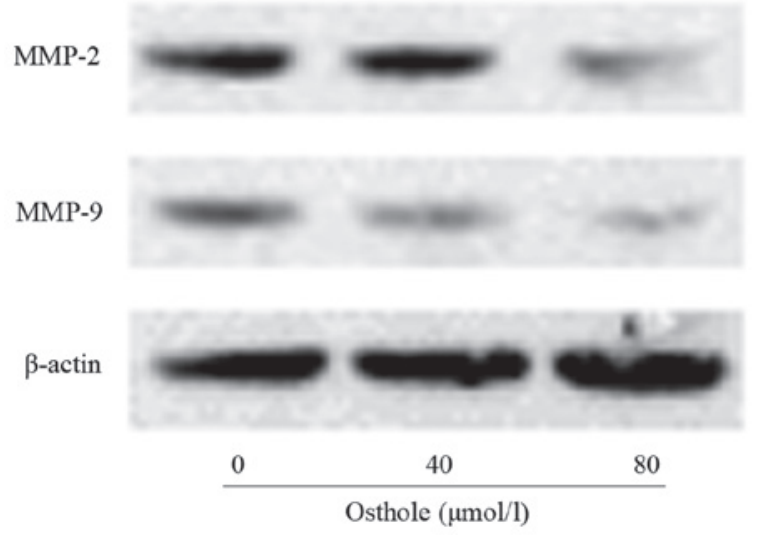

Figure 5. Effect of osthole on the expression of matrix metalloproteinase-2 (MMP-2) and matrix metallopeptidase-9 (MMP-9) by western blot analysis. A549 cells were treated with $(0,40$ and $80 \mu \mathrm{mol} / \mathrm{l})$ osthole for $24 \mathrm{~h}$. Proteins were extracted, then MMP-2 and MMP-9 expression was analyzed by western blotting.

MMP-9 may be responsible for the inhibition of the invasion and migration of A549 cells following exposure to osthole.

\section{Discussion}

The anticancer effects of osthole have been well documented in numerous types of human cancers (13-15). However, the actions of osthole on the migration and invasion of A549 lung cancer cells and the associated mechanisms have not been reported. In the current study, we investigated the effects of osthole on the migration and invasion of A549 cells by Transwell assays and western blot analyses. Our results indicate that osthole inhibited the migration and invasion of the A549 cells and that these effects were dose-dependent. Moreover, the results from the western blot analyses revealed that the mechanism underlying these effects was related to the inhibition of the expression of MMP-2 and MMP-9 in the A549 cells.

Metastasis, the most common cause of treatment failure and death in cancer patients, is a complex biological process in the later stages of cancer progression $(17,18)$. At present, there are no effective therapeutic drugs that are able to specifically treat cancer metastasis, and little is known concerning the molecular mechanisms that regulate the process of metastasis $(19,20)$. Several studies have shown that metastasis is associated with the ability of cells to migrate and invade, and that the inhibition of cell migration and invasion may decrease metastasis (21-23). Therefore, the discovery of drugs that are able to inhibit cancer cell migration and invasion is important for the prevention and treatment of metastasis in lung cancer. In the current study, Transwell migration and matrigel Transwell invasion assays revealed that osthole clearly inhibited the migration and invasion of cells in a concentration-dependent manner. Osthole may have the ability to inhibit the metastasis of human lung cancer.

MMPs comprise a rapidly growing family of structurally related endopeptidases capable of degrading all known components of the extracellular matrix (ECM). Among MMPs, MMP-2 and MMP-9 are vital in the degradation of the ECM due to their substrate specificity toward type IV collagen, the major component of basement membranes $(24,25)$. High expression levels of MMP-2 and MMP-9 have frequently been correlated with increased cancer metastasis in lung cancer $(26,27)$. To further elucidate the mechanisms by which osthole inhibits the migration and invasion of human lung cancer cells, we investigated the effects of osthole on MMP-2 and MMP-9 in A549 cells. In our experiment, treatment with osthole decreased the expression levels of MMP-2 and MMP-9 in a dose-dependent manner. Our results revealed that osthole inhibited the levels of MMP-2 and MMP-9 involved in the migration and invasion in A549 cells, which is in agreement with reports that osthole inhibited the migration and invasion of breast cancer cells via inhibition of the expression of MMP-2 (28).

In conclusion, our data indicate for the first time that osthole inhibits the migration and invasion of A549 human lung cancer cells by inhibiting the expression of MMP-2 and MMP-9. Osthole should be considered as a possible therapeutic agent for inhibiting the metastasis of lung cancer. Further investigations will be required to assess the potential of osthole in the treatment of cancer.

\section{References}

1. Parkin DM, Bray F, Ferlay J and Pisani P: Global cancer statistics, 2002. CA Cancer J Clin 55: 74-108, 2005.

2. Jemal A, Siegel R, Ward E, Hao Y, Xu J, Murray T and Thun MJ: Cancer statistics, 2008. CA Cancer J Clin 58: 71-96, 2008.

3. Molina JR, Yang P, Cassivi SD, Schild SE and Adjei AA: Non-small cell lung cancer: epidemiology, risk factors, treatment, and survivorship. Mayo Clin Proc 83: 584-594, 2008.

4. Erridge SC, Møller H, Price A and Brewster D: International comparisons of survival from lung cancer: pitfalls and warnings. Nat Clin Pract Oncol 4: 570-577, 2007.

5. Wang T, Nelson RA, Bogardus A and Grannis FW Jr: Five-year lung cancer survival: which advanced stage nonsmall cell lung cancer patients attain long-term survival? Cancer 116: 1518-1525, 2010.

6. Gupta GP and Massagué J: Cancer metastasis: building a framework. Cell 127: 679-695, 2006.

7. Yilmaz M, Christofori G and Lehembre F: Distinct mechanisms of tumor invasion and metastasis. Trends Mol Med 13: 535-541, 2007.

8. Guh JH, Yu SM, Ko FN, Wu TS and Teng CM: Antiproliferative effect in rat vascular smooth muscle cells by osthole, isolated from Angelica pubescens. Eur J Pharmacol 298: 191-197, 1996.

9. Ko FN, Wu TS, Liou MJ, Huang TF and Teng CM: Vasorelaxation of rat thoracic aorta caused by osthole isolated from Angelica pubescens. Eur J Pharmacol 219: 29-34, 1992.

10. Zimecki M, Artym J, Cisowski W, Mazol I, Włodarczyk M and Gleńsk M: Immunomodulatory and anti-inflammatory activity of selected osthole derivatives. Z Naturforsch C 64: 361-368, 2009.

11. Cai J, Yu B, Xu G and Wu J: Studies on the quality of fructus Cnidii-comparison of antibacterial action. Zhongguo Zhong Yao Za Zhi 16: 451-453, 510, 1991 (In Chinese).

12. Matsuda H, Tomohiro N, Ido Y and Kubo M: Anti-allergic effects of cnidii monnieri fructus (dried fruits of Cnidium monnieri) and its major component, osthol. Biol Pharm Bull 25: 809-812, 2002.

13. Hung CM, Kuo DH, Chou CH, Su YC, Ho CT and Way TD: Osthole suppresses hepatocyte growth factor (HGF)-induced epithelial-mesenchymal transition via repression of the c-Met/Akt/mTOR pathway in human breast cancer cells. J Agric Food Chem 59: 9683-9690, 2011.

14. Chou SY, Hsu CS, Wang KT, Wang MC and Wang CC: Antitumor effects of Osthol from Cnidium monnieri: an in vitro and in vivo study. Phytother Res 21: 226-230, 2007.

15. Yang LL, Wang MC, Chen LG and Wang CC: Cytotoxic activity of coumarins from the fruits of Cnidium monnieri on leukemia cell lines. Planta Med 69: 1091-1095, 2003. 
16. Xu X, Zhang Y, Qu D, Jiang T and Li S: Osthole induces G2/M arrest and apoptosis in lung cancer A549 cells by modulating PI3K/Akt pathway. J Exp Clin Cancer Res 30: 33, 2011.

17. Nguyen DX, Bos PD and Massagué J: Metastasis: from dissemination to organ-specific colonization. Nat Rev Cancer 9: 274-284, 2009.

18. Lazennec G and Richmond A: Chemokines and chemokine receptors: new insights into cancer-related inflammation. Trends Mol Med 16: 133-144, 2010.

19. Zlotnik A: Chemokines and cancer. Int J Cancer 119: 2026-2029, 2006.

20. Nguyen DX and Massagué J: Genetic determinants of cancer metastasis. Nat Rev Genet 8: 341-352, 2007.

21. Ho YT, Yang JS, Li TC, Lin JJ, Lin JG, Lai KC, Ma CY, Wood WG and Chung JG: Berberine suppresses in vitro migration and invasion of human SCC-4 tongue squamous cancer cells through the inhibitions of FAK, IKK, NF-kappaB, u-PA and MMP-2 and -9. Cancer Lett 279: 155-162, 2009.

22. Wang L, Ling Y, Chen Y, Li CL, Feng F, You QD, Lu N and Guo QL: Flavonoid baicalein suppresses adhesion, migration and invasion of MDA-MB-231 human breast cancer cells. Cancer Lett 297: 42-48, 2010.
23. Ni L, Feng Y, Wan H, Ma Q, Fan L, Qian Y, Li Q, Xiang Y and Gao B: Angiotensin-(1-7) inhibits the migration and invasion of A549 human lung adenocarcinoma cells through inactivation of the PI3K/Akt and MAPK signaling pathways. Oncol Rep 27: 783-790, 2012

24. Hua H, Li M, Luo T, Yin Y and Jiang Y: Matrix metalloproteinases in tumorigenesis: an evolving paradigm. Cell Mol Life Sci 68: 3853-3868, 2011

25. Roomi MW, Monterrey JC, Kalinovsky T, Niedzwiecki A and Rath M: Modulation of MMP-2 and MMP-9 by cytokines, mitogens and inhibitors in lung cancer and malignant mesothelioma cell lines. Oncol Rep 22: 1283-1291, 2009.

26. Park JK, Park SH, So K, Bae IH, Yoo YD and Um HD: ICAM-3 enhances the migratory and invasive potential of human non-small cell lung cancer cells by inducing MMP-2 and MMP-9 via Akt and CREB. Int J Oncol 36: 181-192, 2010.

27. Hung WC, Tseng WL, Shiea J and Chang HC: Skp2 overexpression increases the expression of MMP-2 and MMP-9 and invasion of lung cancer cells. Cancer Lett 288: 156-161, 2010.

28. Yang D, Gu T, Wang T, Tang Q and Ma C: Effects of osthole on migration and invasion in breast cancer cells. Biosci Biotechnol Biochem 74: 1430-1434, 2010. 